\title{
Ten-year comparison of pericardial tissue valves versus mechanical prostheses for aortic valve replacement in patients younger than 60 years of age
}

\author{
Alberto Weber, MD, Hassan Noureddine, MS, Lars Englberger, MD, Florian Dick, MD, Brigitta Gahl, MS, \\ Thierry Aymard, MD, Martin Czerny, MD, Hendrik Tevaearai, MD, Mario Stalder, MD, and \\ Thierry Pierre Carrel, MD
}

Objective: Aortic valve replacement using a tissue valve is controversial for patients younger than 60 years old. The long-term survival in this age group, the expected event rates during long-term follow-up, and valve-related complications are not clearly determined.

Methods: From January 2000 to December 2009 , overall survival, valve-related events, and echocardiographic
outcomes were analyzed in all patients younger than 60 years of age, who underwent biologic aortic valve
replacement. Patients who received a Perimount Carpentier-Edwards pericardial tissue valve $(\mathrm{n}=103$ ) were
selected and compared with a propensity matched group of 103 patients who received aortic valve replacement
using a mechanical bileaflet valve. The mean follow-up was $33 \pm 24$ months (range, $2-120)$, and the mean age at
implantation was $50.6 \pm 8.8$ years (bioprosthesis, $55 \pm 8.9$ years; mechanical valve, $50 \pm 8.6$ years; $P=.03$ ).

Results: Survival was significantly reduced in patients after biologic aortic valve replacement $(90.3 \%$ vs $98 \%$; $P=.038$ ). Freedom from all valve-related complications (bioprosthesis, $54.5 \%$; mechanical valve, $51.6 \%$; $P=\mathrm{NS}$ ) and freedom from reoperation (bioprostheses, $100 \%$; mechanical valve, $98 \% ; P=\mathrm{NS}$ ) were comparable in both groups. The average transvalvular mean $(11.2 \pm 4.2 \mathrm{~mm} \mathrm{Hg}$ vs $10.5 \pm 6.0 \mathrm{~mm} \mathrm{Hg}, P=.05)$ and peak $(19.9 \pm 6.7 \mathrm{~mm} \mathrm{Hg}$ vs $16.7 \pm 8.0 \mathrm{~mm} \mathrm{Hg}, P=.03)$ gradients were greater after biologic aortic valve replacement. Regression of the left ventricular mass index was more pronounced after mechanical valve replacement $\left(118.5 \pm 24.9 \mathrm{~g} / \mathrm{m}^{2}\right.$ vs $\left.126.5 \pm 38.5 \mathrm{~g} / \mathrm{m}^{2} ; P=\mathrm{NS}\right)$. The echocardiographic patient-prosthesis mismatch was greater at follow-up after biological aortic valve replacement $\left(0.876 \pm 0.2 \mathrm{~cm}^{2} / \mathrm{m}^{2}\right.$ vs $1.11 \pm 0.4 \mathrm{~cm}^{2} / \mathrm{m}^{2}$; $P=.01)$. Oral anticoagulation was a protective factor for survival among the bioprosthetic valve patients $(P=.024)$.

Conclusions: In the present limited cohort of patients younger than 60 years old, biologic aortic valve replacement was associated with reduced mid-term survival compared with survival after mechanical aortic valve replacement. Despite similar valve-related event rates in both groups, the better hemodynamic performance of the mechanical valves and/or protective effect of oral anticoagulation seemed to improve the outcome. The transcatheter valve-in-valve intervention as potential treatment of tissue valve degeneration should not be considered the sole bailout strategy for younger patients because no evidence is available that this would improve the outcome. (J Thorac Cardiovasc Surg 2012;144:1075-83)

The current guidelines for aortic valve replacement (AVR) recommend the insertion of a bioprosthesis in patients of any age who are reluctant to receive lifelong warfarin or who have major medical contraindications to anticoagulant therapy. ${ }^{1}$ Compared with previous recommendations, a clear age cutoff for the choice of a tissue valve is no longer

\footnotetext{
From the Department of Cardiovascular Surgery, Inselspital, Bern University Hospital and University of Berne, Berne, Switzerland.

Disclosures: Authors have nothing to disclose with regard to commercial support.

Received for publication July 6, 2011; revisions received Dec 7, 2011; accepted for publication Jan 4, 2012; available ahead of print Feb 20, 2012.

Address for reprints: Alberto Weber, MD, Department of Cardiovascular Surgery, Inselspital, Bern University Hospital and University of Berne, Berne, Switzerland (E-mail: alberto.weber@insel.ch).

$0022-5223 / \$ 36.00$

Copyright (c) 2012 by The American Association for Thoracic Surgery

doi:10.1016/j.jtcvs.2012.01.024
}

considered a major selection criterion. Thus, the use of bioprosthetic valves has markedly increased in the past decade and has led to a substantial reduction of mechanical valve implantations. ${ }^{2}$ This trend might be justified because an increasing number of reports have described the improved long-term durability of the most recent tissue valve models with low rates of structural valve deterioration (SVD). ${ }^{3}$ In addition, current advances in transcatheter valve technology have made valve-in-valve implantation feasible. ${ }^{4-7}$ This option opens new horizons to treat bioprosthetic valve degeneration by way of percutaneous procedures and is currently used by invasive cardiologists as an argument to recommend biologic AVR for younger patients.

Nevertheless, biologic AVR in patients younger 60 years old remains controversial, and the expected event rates for surgical and valve-related complications have not been 


\section{Abbreviations and Acronyms \\ $\mathrm{AVR}=$ aortic valve replacement \\ EOAI = effective orifice area index \\ MAPEs $=$ major adverse prosthesis-related events \\ PPM = patient-prosthesis mismatch \\ SVD = structural valve deterioration}

clearly determined for this subset of patients. In the present study, we analyzed the clinical outcomes after biologic and mechanical AVR in patients 60 years old or younger.

\section{METHODS}

\section{Setting and Study Population}

A consecutive series of patients undergoing AVR from January 2000 to December 2009 was identified from a prospectively compiled database and screened for the following inclusion criteria: AVR at age 60 years or younger, isolated or with concomitant procedures such as coronary artery bypass grafting, ascending or aortic root surgery, and mitral or tricuspid valve repair. The exclusion criterion was additional valve replacement.

Only patients who received a stented Carpentier-Edwards xenopericardial tissue valve (model 3000TFX and 3300TFX, Edwards Lifesciences, Irvine, Calif) were selected. The control group included patients who received mechanical bi-leaflet aortic valve replacement (St Jude Medical, Minneapolis, MI, or ATS Medical, Plymouth, MI) during the same period. These valves were chosen, because they are the most commonly used implants at our institution.

In the setting of a retrospective study, we used propensity matching to improve comparability and to reduce selection bias. ${ }^{8,9}$ The investigators were kept unaware of the outcomes during the matching process (Figure 1).

The patient data were prospectively recorded in a computerized database or retrieved from hospital charts. All patients provided written informed consent to use the data for study purposes. Clinical follow-up was conducted at our institution or through contact with the patients' cardiologist or general practitioner. In addition, routine echocardiographic follow-up was performed for all patients. All patients were contacted for a questionnaire survey.

The patients with a mechanical valve prosthesis postoperatively received lifelong warfarin anticoagulation, with a target of the international normalized ratio of 2.0 to 2.5. Patients with aortic bioprostheses received lifelong aspirin only.

\section{Statistical Analysis}

A number of differences in patient characteristics precluded unadjusted comparisons of outcomes. To reduce selection bias, we used propensity matching to approximate a randomized trial. ${ }^{10}$ Of all preoperatively known variables, we identified 9 factors potentially correlated with the valve choice ( $P \leq .1$ on bivariate analysis): pulmonary arterial hypertension, active endocarditis, coagulation disorder, cancer, instable hemodynamic, emergency status, concomitant procedures, preoperative need for antifibrinolytic agents, and preoperative need for inotropic drugs. These potential confounders were included in the logistic regression model. A propensity score was calculated for each patient by solving the resulting propensity models for the probability of receiving a bioprosthetic valve. ${ }^{11}$ Using only the propensity score, the bioprosthetic valve patients were matched with the mechanical valve patients by "greedy" matching. ${ }^{8} \mathrm{~Pa}$ tients with bioprosthetic valves whose propensity scores deviated more than 0.1 from those with mechanical valves were considered unmatched (Table 2).
Continuous normally distributed variables are presented as the mean \pm standard deviation. Non-normally distributed continuous variables are presented as the median and interquartile range. A bivariate comparison was performed in paired design, using the Wilcoxon signed-rank test or paired Student's $t$ test, if appropriate. For categorical variables, we used the McNemar test. Cumulative survival was estimated using the KaplanMeier method. We used uni- and multivariate Cox proportional hazard regression models that accounted for the matching to estimate the independent effect of valve type, after adjustment for other suspected confounding factors, including age, hypertension, renal failure, logistic European System for Cardiac Operative Risk Evaluation, American Society of Anesthesiologists classification, preoperative ejection fraction, valve replacement for endocarditis, functional valve pathology, aortic stenosis, aortic insufficiency, concomitant coronary artery bypass grafting, New York Heart Association class, and aortic dissection. Effect is reported as the $P$ value, hazard ratio, and $95 \%$ confidence intervals. Two-tailed tests of significance are reported.

Statistical analysis was performed using the Statistical Package for Social Sciences, version 17.0, for Windows (SPSS, Chicago, IL) and Stata11 (StataCorp, College Station, Tex).

\section{Study Endpoints}

The primary study endpoints included overall survival and cardiacrelated mortality, SVD (defined as reoperation for valve failure and/or patient-prosthesis mismatch [PPM]), determined by echocardiography as the effective orifice area index (EOAI), and reoperation. Sudden, unexplained death was considered cardiac-related mortality. The secondary endpoints were echocardiographic follow-up (left ventricular ejection fraction, transvalvular gradients, and left ventricular mass and dimensions) and major adverse prosthesis-related events (MAPEs) according to the guidelines for reporting mortality and morbidity after cardiac valve intervention. ${ }^{12}$ Perioperative EOAIs were as anticipated by reference tables and individual body surface area assessment. The follow-up EOAIs were determined by echocardiographic measurement of the prosthesis valve area and individual body surface area assessment.

\section{RESULTS}

From January 2000 to December 2009, a total of 1864 patients underwent AVR at our institution. During the study period, the number of AVRs increased from 173 in 2000 to 447 during 2009. A total of 440 patients were younger than 60 years of age in the study period (biologic AVR for 201 and mechanical AVR for 239).

The final study population consisted of 103 patients who received a Carpentier-Edwards biologic AVR and 103 patients who received a mechanical AVR and constituted the propensity-matched group. The preoperative patient characteristics of both study groups are presented in Table 1. No statistically significant differences were observed in the matched parameters; however, age and the incidence of acute aortic dissection differed between the 2 groups and were adjusted for in the multivariate analysis. The mean and median follow-up period was $33 \pm 24$ and 29 months (range, 2-120), respectively, and the survival status was known for $97 \%$ of the patients. Complete echocardiographic follow-up data were available for $78.3 \%$ of the patients. We observed 12 events (deaths) per 548 patient-valve years.

The early outcomes did not significantly differ between the 2 groups. Five patients died within 90 days postoperatively in 


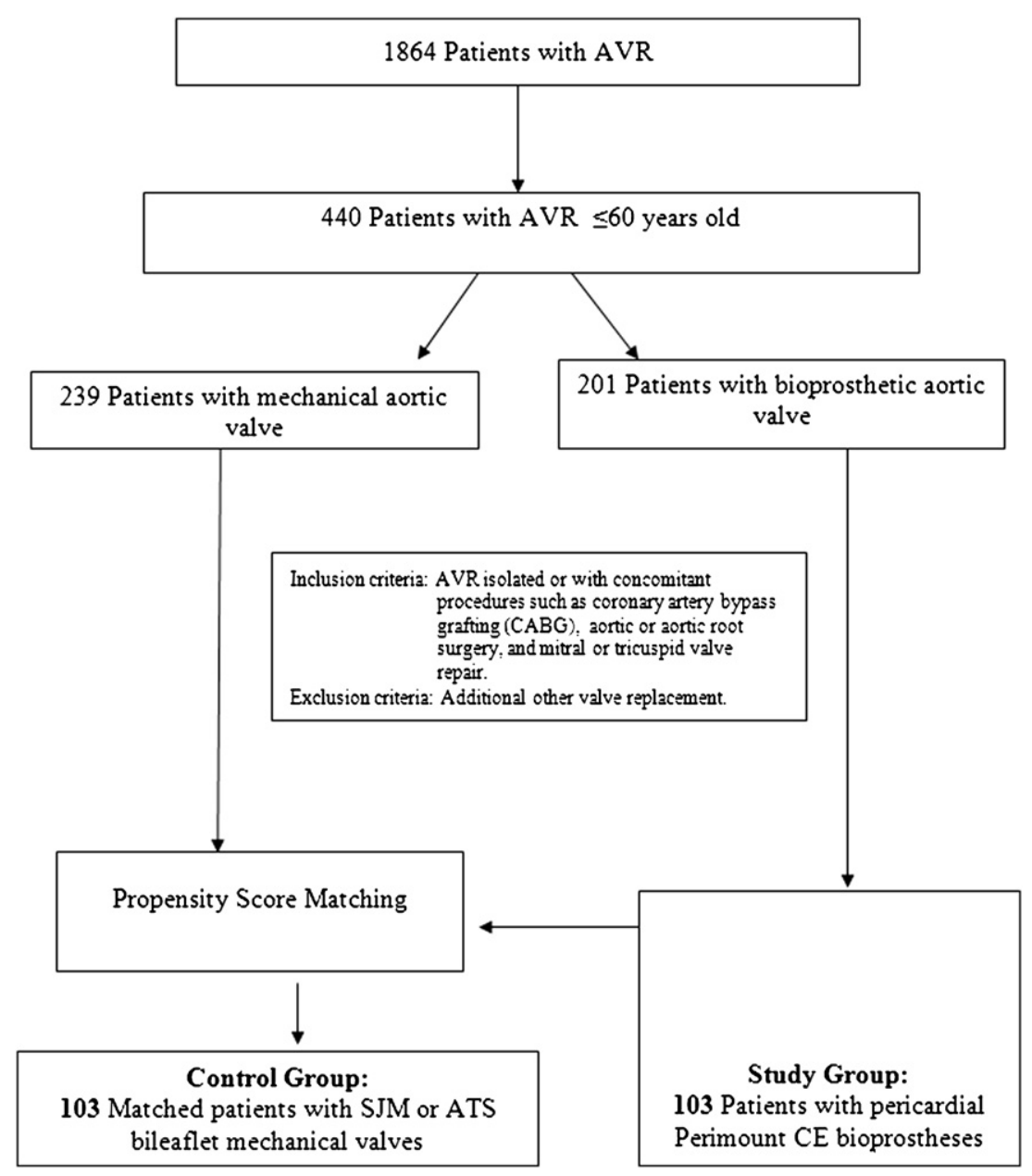

FIGURE 1. Flow chart of study population selection. AVR, aortic valve replacement; SJM, St Jude Medical; ATS, ATS Medical; CE, Carpentier-Edwards.

the biologic AVR group (1 patient died of multiorgan failure, 2 patients without special comorbidities died of sudden cardiac arrest, and 2 patients died of prosthesis endocarditis). More patients underwent reexploration for bleeding complications after mechanical AVR; however, this difference did not reach statistical significance $(17[16.5 \%]$ vs 7 [6.8\%]; $P=.052$ ).

During the follow-up period (Figure 2), 10 patients who had undergone biologic AVR died (0.05 death/patient-year) compared with 2 patients who had undergone mechanical AVR (0.009 death/patient-year). Cox proportional hazard regression analysis suggested that patients who received a biologic valves were more likely to die during follow-up than those who received a mechanical valve (hazard ratio, $0.243 ; 95 \%$ confidence interval, $0.054-0.923 ; P=.038$; Table 3). The cause of death in the biologic AVR group was sudden cardiac death in 5 patients, as stated in the death reports. Only 2 patients underwent an autopsy; 1 showed endocarditis signs and a possible coronary embolization. Another patient presented with an unknown advanced lung tumor. The cause of death in the mechanical AVR group was hemorrhagic stroke in 1 and suicide in 1 patient. Atrial fibrillation was reported more frequently in the biologic AVR group $(P=.01)$, but MAPE did not seem to differ between the study groups (Table 4). Freedom from reoperation on the aortic valve did not differ between the 2 groups $(100 \%$ vs $98 \% ; P=.231)$. Only 2 patientsboth after mechanical AVR-required surgical repeat replacement of the prosthesis; both had developed prosthetic valve endocarditis.

The echocardiographic follow-up examination was performed at a mean interval of $21.8 \pm 19.8$ months (range, 6-84) after AVR. Greater mean (11.2 $\pm 4.2 \mathrm{~mm} \mathrm{Hg}$ vs 10.2 $\pm 6.0 \mathrm{~mm} \mathrm{Hg}, P=.05)$ and peak $(19.9 \pm 6.7 \mathrm{~mm} \mathrm{Hg}$ vs $16.7 \pm 8.0 \mathrm{~mm} \mathrm{Hg}, P=.03)$ transvalvular aortic gradients were detected in the biologic AVR group. Patients after mechanical AVR tended to have better left ventricular mass index regression $\left(118.5 \pm 24.9 \mathrm{~g} / \mathrm{m}^{2}\right.$ vs $126.5 \pm 38.5 \mathrm{~g} / \mathrm{m}^{2}$; $P=.056)$. The mean preoperative left ventricular mass index was $165.57 \pm 56.8 \mathrm{~g} / \mathrm{m}^{2}$ in the biologic AVR group and $170.33 \pm 51.44 \mathrm{~g} / \mathrm{m}^{2}$ in the mechanical AVR group $(P=.694)$. The amount of regression in each patient was 
TABLE 1. Preoperative patient characteristics (paired analysis)

\begin{tabular}{|c|c|c|c|}
\hline $\begin{array}{c}\text { Perioperative patient } \\
\text { characteristics } \\
\end{array}$ & $\mathrm{BP}(\mathrm{n}=103)$ & $\mathbf{M P}(\mathbf{n}=\mathbf{1 0 3})$ & $P$ value \\
\hline Age (y) & & & .029 \\
\hline Median & 55 & 50 & \\
\hline IQR & $46-59$ & $45-58$ & \\
\hline Male & $86(83.5)$ & $87(84.5)$ & .612 \\
\hline $\begin{array}{l}\text { NYHA functional } \\
\text { class III or IV }\end{array}$ & $34(33)$ & $23(22.3)$ & .193 \\
\hline Smoking history & $50(48.5)$ & $49(47.6)$ & .889 \\
\hline Diabetes & $10(9.7)$ & $8(7.8)$ & .617 \\
\hline Renal failure & $8(7.8)$ & $4(3.9)$ & .208 \\
\hline Endocarditis & $9(8.7)$ & $7(6.8)$ & .617 \\
\hline Lung disease & $9(8.7)$ & $8(7.8)$ & .808 \\
\hline Coronary heart disease & $25(24.3)$ & $19(18.4)$ & .273 \\
\hline Peripheral vascular disease & $3(2.9)$ & $0(0)$ & .083 \\
\hline Urgent or emergency status & $10(9.7)$ & $14(13.6)$ & .277 \\
\hline $\begin{array}{l}\text { Coronary artery bypass } \\
\text { grafting }\end{array}$ & $23(22.3)$ & $18(17.5)$ & .465 \\
\hline Valve size $(\mathrm{mm})$ & & & .95 \\
\hline Median & 25 & 25 & \\
\hline IQR & $23-27$ & $23-27$ & \\
\hline Ejection fraction $(\%)$ & & & .814 \\
\hline Median & 60 & 60 & \\
\hline IQR & $50-65$ & $50-65$ & \\
\hline Aortic valve insufficiency & $81(78.6)$ & $72(69.9)$ & .139 \\
\hline None & $22(21.4)$ & $31(30.1)$ & \\
\hline Mild & $27(26.2)$ & $12(11.7)$ & \\
\hline Moderate & $30(29.1)$ & $32(31.1)$ & \\
\hline Severe & $24(23.3)$ & $28(27.2)$ & \\
\hline Aortic valve stenosis & $60(58.3)$ & $44(42.7)$ & .238 \\
\hline None & $43(41.7)$ & $59(57.3)$ & \\
\hline Mild & $7(6.8)$ & $5(4.9)$ & \\
\hline Moderate & $15(14.6)$ & $14(13.6)$ & \\
\hline Severe & $38(36.9)$ & $26(25.2)$ & \\
\hline Previous cardiac surgery & $7(6.8)$ & $11(10.7)$ & .454 \\
\hline Acute aortic dissection & $1(1.0)$ & $10(9.7)$ & .007 \\
\hline Composite graft & $22(20.4)$ & $34(36.2)$ & .181 \\
\hline Body surface area $\left(\mathrm{m}^{2}\right)$ & $1.9 \pm 0.17$ & $1.9 \pm 0.22$ & 1 \\
\hline Body mass index $\left(\mathrm{kg} / \mathrm{m}^{2}\right)$ & & & .877 \\
\hline Median & 25.6 & 26.4 & \\
\hline IQR & $23.18-28.24$ & $22.99-29.73$ & \\
\hline Logistic euroScore & & & .445 \\
\hline Median & 4.65 & 4.65 & \\
\hline IQR & $2.27-8.96$ & $2.27-10.05$ & \\
\hline ECC time (min) & $113.13 \pm 62.04$ & $106.13 \pm 51.07$ & .387 \\
\hline Crossclamp time (min) & $80.61 \pm 34.34$ & $76.24 \pm 31.71$ & .351 \\
\hline
\end{tabular}

$P$ values for paired analysis. $B P$, Bioprosthesis; $M P$, mechanical prosthesis; $I Q R$, interquartile range; NYHA, New York Heart Association; euroScore, European System for Cardiac Operative Risk Evaluation; ECC, extracorporeal circulation.

$-38.7 \pm 61.3 \mathrm{~g} / \mathrm{m}^{2}$ in the biologic AVR group and $-54.8 \pm$ $42.7 \mathrm{~g} / \mathrm{m}^{2}$ in the mechanical AVR group $(P=.291)$. Echocardiographically determined PPM was more often observed in patients after biologic AVR (EOAI, $0.876 \pm 0.219 \mathrm{~cm}^{2} / \mathrm{m}^{2}$ vs EOAI, $1.11 \pm 0.39 \mathrm{~cm}^{2} / \mathrm{m}^{2}, P=.01$; Figure 3). Stratification by PPM severity is listed in Table 5 .
The results of the questionnaire survey included information about the different clinical practice between the 2 study groups. In our series, $81 \%$ of patients received specific information about the different valve types before their index surgery admission and already had preferences for the valve type that was finally implanted. Fourteen percent of the patients received warfarin after biologic AVR, most because of atrial fibrillation (Table 4). After mechanical AVR, $3.2 \%$ of the patients were treated with a combination of aspirin and clopidogrel only, and 1 patient received no anticoagulation at all. In the biologic AVR group, only $57 \%$ of patients had received aspirin or clopidogrel at the questionnaire survey, although $7.3 \%$ of the patients with a mechanical valve had received combined therapy of warfarin and aspirin or clopidogrel. However, the bioprosthetic valve patients with oral anticoagulation for atrial fibrillation were more likely to survive during the follow-up period, suggesting a protective effect of oral anticoagulation $(P=.024)$.

\section{DISCUSSION}

The current guidelines for AVR do not consider patient age as a major selection criterion for the decision regarding which valve type should be recommended for AVR. ${ }^{1}$ Several reasons support the increasing use of bioprosthetic valves for AVR in the younger patient population aged 60 years or younger, including the better quality of life without warfarin and without the perceptible noise of a mechanical prosthesis, the excellent long-term durability of current tissue valves with low rates of SVD, and the progress in anesthesiologic and surgical techniques with a accompanying decrease in operative risk for redo-AVR procedures. ${ }^{3,13-15}$ In addition, the choice between a mechanical or tissue valve in adults is also determined by estimating the patient's compliance with lifelong drug treatment and the risk of anticoagulation-related bleeding and embolic events with a mechanical valve versus the risk of SVD with a tissue valve. The possibility of treating tissue valve failure using transcatheter valve-in-valve implantation might decrease the risk of surgical reintervention, although current evidence is lacking to consider it a valid alternative to surgery. However, this option is currently frequently used by cardiologists to convince younger patients of the benefits of biologic valves. ${ }^{4,5,16}$

Long-term survival data from younger patients after biologic versus mechanical AVR are rare and the relative risks and benefits of biologic AVR in this population have not been clearly determined.

The present propensity-matched study included 206 patients 60 years old or younger who underwent AVR with bioprosthetic and mechanical valves. Our findings were as follows. First, survival seemed better after mechanical AVR. Second, mid-term echocardiographic studies suggested-against our expectations - an early onset of 
TABLE 2. Results of Cox regression analysis, accounting for matched design

\begin{tabular}{lllrrr}
\hline \multicolumn{1}{c}{ Variable } & \multicolumn{1}{c}{ HR } & Robust SE & $\mathbf{z}$ & $\boldsymbol{P}>\mathbf{z}$ & $\mathbf{9 5} \% \mathbf{C I}$ \\
\hline Age & 1.063 & 0.063 & 1.04 & .297 & $0.9470-1.1951$ \\
Hypertension & 0.9335984 & 0.7164458 & -0.09 & .929 & $0.2074655-4.20121$ \\
Renal failure & 3.475436 & 3.285754 & 1.32 & .188 & $0.5448345-22.16941$ \\
Logistic euroScore & 1.0218 & 0.0182618 & 1.04 & .300 & $0.9828658-1.057604$ \\
ASA & 3.450743 & 1.922925 & 2.22 & .026 & $1.15766-10.28595$ \\
Active endocarditis & 1.211325 & 1.402717 & 0.17 & .869 & $0.1251894-11.7207$ \\
Acute aortic dissection & $2.24 \mathrm{e}-20$ & & & \\
Ejection fraction & 1.0158 & 0.0241919 & 0.66 & .509 & $0.9695078-1.064373$ \\
Functional & $6.06 \mathrm{e}-21$ & & & .295 & \\
AS & 0.4628319 & 0.3402517 & -0.05 & .993 & $0.1095622-1.955175$ \\
AI & 9911871 & 0.9804856 & -0.01 & .059 & $0.1426081-6.889173$ \\
Concomitant CABG & 3.909154 & 2.816544 & 1.89 & .203 & $0.9523407-15.98522$ \\
Type of aortic valve & 0.2766136 & 0.2789901 & -1.27 & .126 & $0.0383141-1.997046$ \\
NYHA & 2.0081 & 0.9154 & 1.53 & .126 & $0.8217568-4.907169$ \\
\hline
\end{tabular}

HR, Hazard ratio; SE, standard error; CI, confidence interval; euroScore, European System for Cardiac Operative Risk Evaluation; ASA, American Society of Anesthesiologists; $A S$, aortic stenosis, $A I$, aortic insufficiency; $C A B G$, coronary artery bypass grafting; $N Y H A$, New York Heart Association.

SVD in pericardial bioprostheses, leading to premature occurrence of moderate PPM. Finally, and more surprisingly, the incidence of MAPEs or the need for reoperation was comparable in both groups. Our results have confirmed the findings of the most well-known randomized trial, which showed better survival for patients after mechanical AVR than for those with biologic AVR. The Department of Veterans Affairs randomized trial ${ }^{17}$ revealed that the use of mechanical valves in AVR resulted in a lower mortality rate, with the difference between biologic and mechanical AVR becoming apparent after 10 years $(66 \% \pm 3 \%$ vs $79 \% \pm 3 \%, P=.02)$. In the second large historical trial (Edinburgh Heart Valve Trial), ${ }^{18}$ a survival advantage for mechanical valves was present at 12 years; however, the actuarial survival curves between the groups converged at 20 years of follow-up.

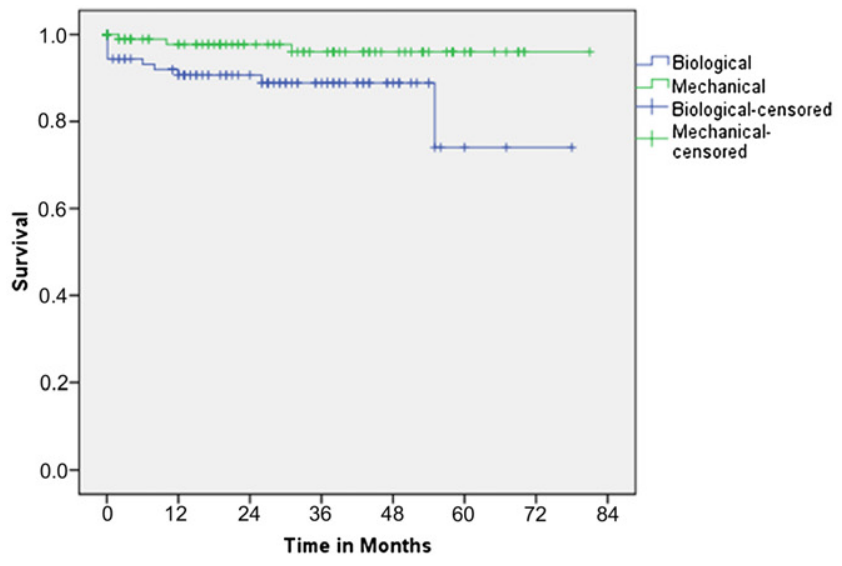

\begin{tabular}{|l|c|c|c|c|c|c|c|}
\hline $\begin{array}{l}\text { Months after } \\
\text { AVR }\end{array}$ & 0 & 12 & 24 & 36 & 48 & 60 & 72 \\
\hline $\begin{array}{l}\text { Patients at } \\
\text { risk: }\end{array}$ & & & & & & & \\
\hline Bioprosihesis & 103 & 72 & 51 & 33 & 14 & 3 & 1 \\
\hline Mechancial & 103 & 81 & 61 & 48 & 30 & 12 & 1 \\
\hline
\end{tabular}

Recently, an analysis of 41,227 patients after aortic valve surgery from the Society for Cardiothoracic Surgery of Great Britain and Ireland national database ${ }^{19}$ demonstrated that the estimated survival of patients with a biologic valve was significantly lower than that of patients with a mechanical valve. The hazard ratio for improved survival was 1.46 (95\% confidence interval, 1.35-1.57) if the patients had received a mechanical aortic valve.

In contrast, a more recent prospective randomized trial by Stassano and associates ${ }^{20}$ demonstrated a similar survival rate 13 years after biologic or mechanical AVR. Randomized clinical trials represent the best evidence regarding the risks and benefits for patients after implantation of biologic or mechanical valves; however, as already emphasized by others, randomization is a difficult task in such populations. $^{20,21}$ In the present series, $81 \%$ of patients already

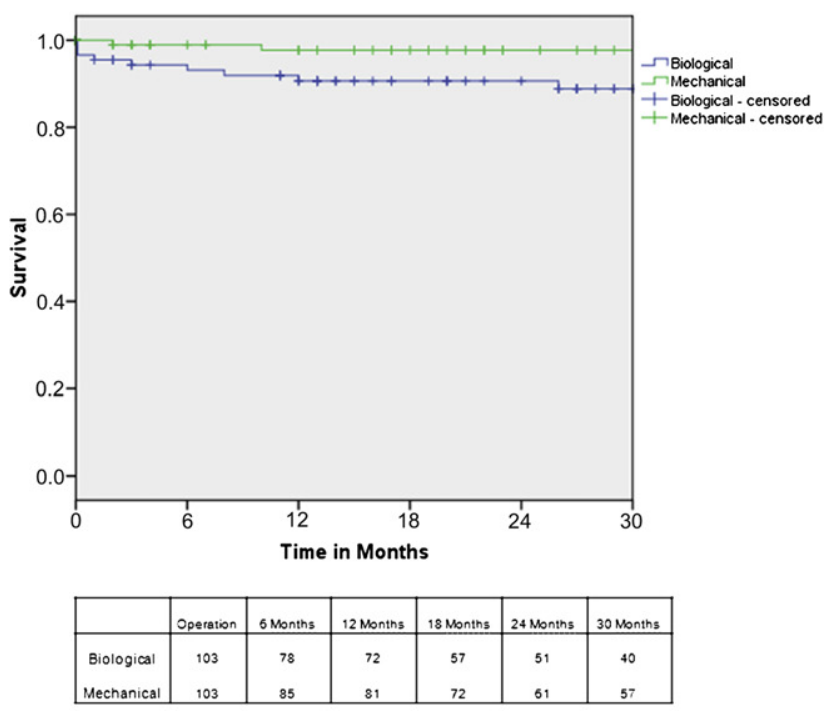

B

FIGURE 2. A, Kaplan-Meier actuarial survival. B, Truncated curve at 10 patients. $A V R$, aortic valve replacement. 
TABLE 3. Odds ratios after bioprosthetic versus mechanical AVR

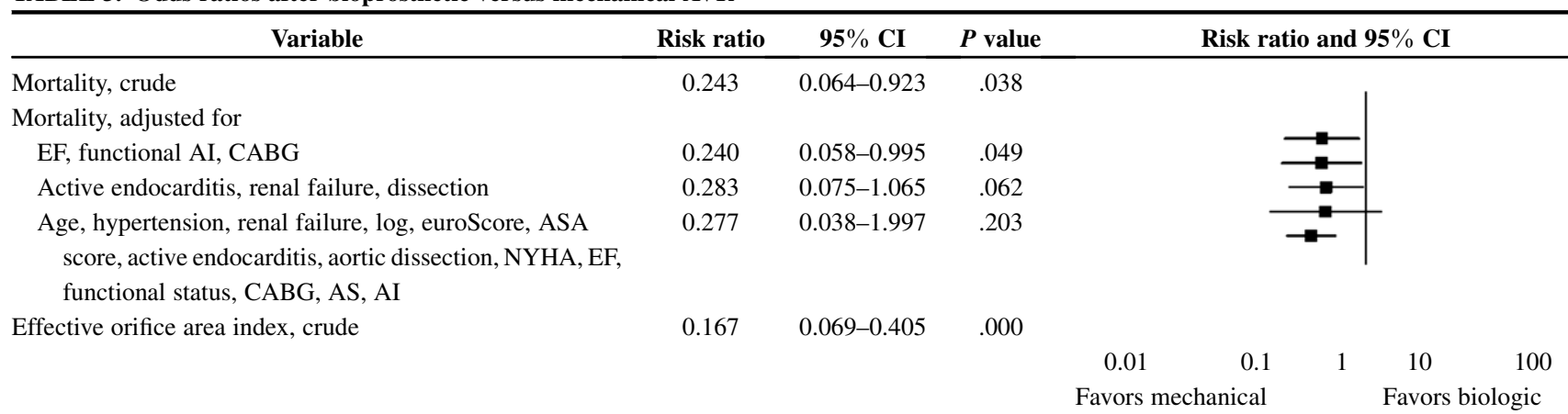

Forest plot from univariate ("crude") and multivariate Cox proportional hazard models that accounted for clustering of pair-matched patients to compare the effect of mechanical versus biologic valve replacement therapy on overall survival and effective orifice area. $P$ values were calculated using 2-sided Wald test derived from Cox proportional hazard models. $A V R$, Aortic valve replacement; $C I$, confidence interval; $E F$, ejection fraction; $A I$, aortic insufficiency; $C A B G$, coronary artery bypass grafting; $A S A$, American Society of Anesthesiologists; NYHA, New York Heart Association; $A S$, aortic stenosis.

had a clear opinion concerning the choice of valve type at admission for AVR surgery.

In a retrospective observational study from the Mayo Clinic $^{14}$ that focused on patients aged 50 to 70 years undergoing AVR, those with mechanical valves had a survival advantage compared with matched patients who received bioprostheses. However, conflicting results have been reported. Several retrospective studies could not demonstrate differences in late survival when mechanical versus biologic heart valves were compared..$^{5,21,22-26}$

Although several studies presented data with longer follow-up periods than in our study, most of these studies included older patient populations. The mean age in our entire study cohort was very young for choosing a tissue valve (50.4 \pm 9.3 years), because age has been demonstrated to be a very important factor when life expectancy after AVR is concerned. ${ }^{27}$ In addition, several studies included mixed various bioprosthetic valve types (eg, stented, stentless, porcine, and pericardial valves), which could have introduced additional confounders because significant differences in the SVD rate, survival, and echocardiographic findings exist between the different valve types. ${ }^{28-34}$

Surprisingly, we observed a survival advantage for patients with a mechanical valves after a median interval of only 3 years. This observation was unlikely to be a chance finding. Considering most critically the lower age groups in

TABLE 4. Outcomes at late follow-up ( $>90$ days; those lost to followup excluded)

\begin{tabular}{lccc}
\hline \multicolumn{1}{c}{ Covariate } & $\mathbf{B P}(\mathbf{n}=\mathbf{1 0 0})$ & $\mathbf{M P}(\mathbf{n}=\mathbf{1 0 0})$ & $\boldsymbol{P}$ value \\
\hline Late atrial fibrillation & 12 & 2 & .01 \\
Late endocarditis & 3 & 2 & 1 \\
Late myocardial infarction & 1 & 1 & 1 \\
Late reoperation & 0 & 2 & .231 \\
Late stroke & 3 & 6 & .316 \\
Late cerebral hemorrhage & 0 & 1 & .482 \\
Last NYHA class III or IV & 4 & 4 & .739 \\
\hline
\end{tabular}

BP, Bioprosthesis; MP, mechanical prosthesis; NYHA, New York Heart Association. several long-term studies of bioprostheses ( $>50$ years or $>60$ years), an inflection point in the survival curve has consistently been observed at 5 years after AVR. ${ }^{3,35,36}$

Other possible explanations for the observed difference in the survival rates between the 2 groups should be considered: the observational retrospective character does not exclude that patient characteristics not included in the matching process could have importantly confounded the results. For instance, patients who received a biologic AVR were older (mean age, 55 years vs 50 years; $P=.029)$ at implantation, and more urgent/emergent operations (including acute type $\mathrm{A}$ aortic dissection $[1 \%$ vs $9.7 \% ; P=.007]$ ) were performed in the group of patients who underwent mechanical AVR. We tried to compensate for the bias in patient selection by propensity matching patients with similar comorbidities and a similar extent of aortic valve disease. However, this might not have excluded and/or illustrated that bioprosthetic valves could have

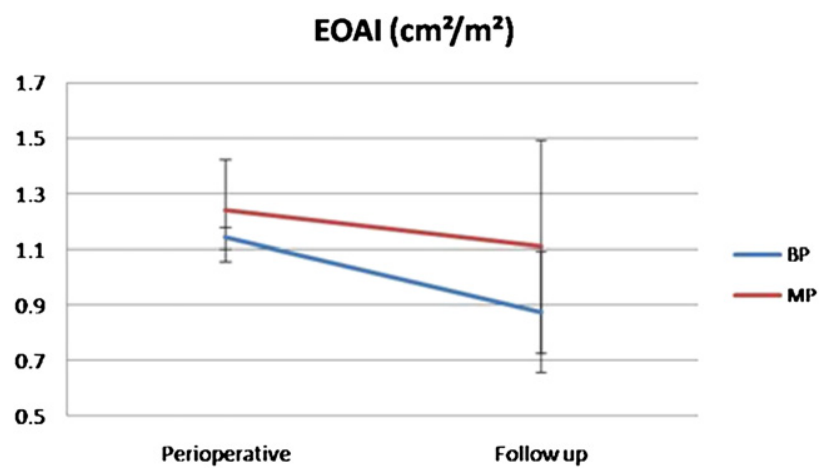

FIGURE 3. Perioperative effective orifice area index (EOAI) anticipated by reference tables and individual body surface area assessment (bioprosthesis $[B P], 1.142 \pm 0.039 \mathrm{~cm}^{2} / \mathrm{m}^{2}$ vs mechanical prosthesis $[M P], 1.24 \pm 0.182 \mathrm{~cm}^{2} / \mathrm{m}^{2} ; P=.599$ ). Follow-up EOAI determined by echocardiographic measurement of prosthesis valve area and individual body surface area assessment (BP, $0.876 \pm 0.219 \mathrm{~cm}^{2} / \mathrm{m}^{2}$ vs MP, $\left.1.11 \pm 0.383 \mathrm{~cm}^{2} / \mathrm{m}^{2} ; P=.01\right)$. 
TABLE 5. EOAI at follow-up (echocardiographic measurements)

\begin{tabular}{|c|c|c|c|c|}
\hline $\begin{array}{c}\text { Severity of PPM } \\
\text { after AVR }\end{array}$ & $\operatorname{EOAI}\left(\mathrm{cm}^{2} / \mathrm{m}^{2}\right)$ & BP $(\%)$ & MP $(\%)$ & $P$ value \\
\hline Mild & $>0.9$ & 48.8 & 63.9 & NS \\
\hline Moderate & $>0.6-0.9$ & 37.3 & 35.1 & NS \\
\hline Severe & $\leq 0.6$ & 13.9 & 0 & .01 \\
\hline
\end{tabular}

EOAI, Effective orifice area index; PPM, prosthesis-patient mismatch; $A V R$, aortic valve replacement; $B P$, bioprosthesis; $M P$, mechanical prosthesis.

been preferably implanted in patients who generally appeared to be more ill and therefore to have a less favorable life expectancy. This hypothesis might even be supported by the fact that during follow-up, more patients in the biologic AVR group had atrial fibrillation, which might be a sign of advanced cardiac disease ${ }^{37}$; however, these patients, of all of the patients, enjoyed a protective effect from oral anticoagulation with regard to early and late survival $(P=.024)$. In contrast, several younger and physically active patients requested a biologic AVR to avoid lifelong warfarin therapy.

In our clinical practice, patients with aortic valve bioprostheses and sinus rhythm receive lifelong aspirin only as antithrombotic treatment. However, in the present study, up to $14 \%$ of patients after bioprosthetic AVR were receiving oral anticoagulation to treat atrial fibrillation. This group of patients presented with $100 \%$ late survival. This finding and the better survival of patients with mechanical valves might suggest a potential protective effect of oral anticoagulation, regardless of the valve type in these young patients. Despite the guidelines issued by several professional societies, the opinions and medical practices related to the prevention of thrombotic events early after implantation of aortic bioprostheses remain conflicting. ${ }^{38-40}$ In addition, the need or not for anticoagulation after bioprosthetic AVR was determined mostly from series with patients older than 60 years.

The risk of SVD is clearly greater for biologic than for mechanical valve prostheses. Patient age at AVR is the most important determinant of SVD during follow-up. ${ }^{27}$ It has been demonstrated ${ }^{21}$ that the risk of major bleeding after mechanical AVR equals the risk of reoperation after biologic AVR in patients aged 60 years at surgery. Despite the excellent long-term follow-up data generated for different types of tissue valves, it cannot be emphasized strongly enough that premature onset of SVD dramatically increases the younger the patient population. In their report on 18 years' experience with the Perimount xenopericardial tissue valve, Aupart and associates ${ }^{41}$ showed freedom from SVD at late follow-up of $99 \% \pm 1 \%$ in patients aged 70 years but as low as $45 \% \pm 15 \%$ in patients younger than 60 years. In the present study, no reoperation was performed because of SVD, mainly owing to the limited observation interval. Because it was clear that we would not see many cases of classic SVD, we focused on the early to mid-term echocardiographic findings ${ }^{42-44}$ and were surprised to observe considerably poorer EOAI values at a mean of $21.8 \pm 19.8$ months in the younger patients after biologic AVR. Because we had adopted a strategy to avoid implantation of valves sized smaller than $21 \mathrm{~mm}$, we expected a minimum of PPM immediately after AVR. In those cases that do not fulfill a minimal size of the annulus of $21 \mathrm{~mm}$, we perform annulus enlargement. All patients in the present trial had a theoretical EOAI of 0.9 $\mathrm{cm}^{2} / \mathrm{m}^{2}$ or greater at implantation (as anticipated by the reference tables). However, it is still possible that the EOAI values might have been worse than expected at surgery, although the observation that EOAI became more narrowed during follow-up might have been a sign of subclinical SVD. Longer echocardiographic follow-up examinations are necessary to elucidate this issue.

Finally, when MAPE are considered, no major difference was seen in the incidence of bleeding events between the 2 groups. The younger age of our patients, the introduction of point of care devices with home international normalized ratio monitoring, and the close patient-physician relationship present in our country might have potentially resulted in lower levels of anticoagulation and therefore decreased the bleeding risk. ${ }^{30}$ The potential of new oral direct thrombin-inhibitors (Rivaroxaban, Dabigatran) as a substitute for warfarin for patients with mechanical valves will be explored in the future.

In agreement with other studies, ${ }^{17,18}$ no difference was found in late thromboembolism between patients with mechanical valves and those with bioprosthetic valves.

Transcatheter aortic valve implantation (TAVI) has emerged as an attractive less-invasive treatment option for patients with symptomatic severe aortic valve stenosis. Currently, patients thought to be at excessive risk of conventional surgical AVR are considered candidates for TAVI. These patients are typically elderly patients with significant comorbidities, usually reflected by a logistic European System for Cardiac Operative Risk Evaluation of more than $20 \%$ or a Society of Thoracic Surgeons risk of mortality of greater than $10 \%$ for perioperative mortality. Patients with other factors that increase surgical risk but not captured by these scoring system (eg, porcelain aorta, previous chest radiation, general frailty) are also deemed appropriate candidates for TAVI. In the most recent period, patients with degeneration of previously implanted tissue valves could also potentially benefit from beating-heart TAVI, eliminating the risks associated with the use of cardiopulmonary bypass and cardiac arrest - even if protected by myocardial protection solutions. Previous animal studies and selected clinical case series have suggested that valve-in-valve TAVI for degenerated bioprostheses is technically feasible and safe. However, the small number of patients undergoing valve-in-valve TAVI reported to date, even at pioneering centers, precludes reliable insights into the clinical success 
and complication rates of valve-in-valve TAVI. This procedure can be performed with high technical success and excellent postprocedural function of the stented valve; however, in these elderly high-risk patients with multiple comorbidities, valve-in-valve TAVI was associated with $17 \%$ mortality, mostly from septic complications. ${ }^{16}$ Many efforts to improve technology, along with better perioperative management, will most probably improve the outcomes of valve-in-valve TAVI in these very high-risk patients.

The limitations of the present trial included that it was a retrospective analysis and as such was subject to selection bias. We tried to compensate for the bias in patient selection by propensity matching patients with similar comorbidities and a similar extent of aortic valve disease. Most importantly, individual matching and analysis plans were agreed on before the data were inspected; thus, we were unaware of the outcomes before the comparison groups were established. However, longer and more complete follow-up with echocardiographic examination is mandatory to confirm our findings.

In conclusion, the present trial adds some practical knowledge regarding the choice of the valve type in patients younger than 60 years of age who require AVR. We observed better survival of patients who received mechanical prostheses in this age group. The implantation of a biologic valve in aortic position in those younger than 60 years seemed to increase the adjusted mortality risk. We have concluded that the evidence is as yet insufficient to recommend bioprosthetic valves, other than in exceptional situations, for younger patients ( $<60$ years) who require AVR. Larger prospective randomized trials are needed to explore these results in more detail. For instance, we suggest a strict randomization between only 2 valves types in isolated AVR and a longer continued echocardiographic analysis of the prosthetic valve areas.

\section{References}

1. Bonow RO, Carabello BA, Chatterjee K, et al. ACC/AHA 2006 guidelines for the management of patients with valvular heart disease. J Am Coll Cardiol. 2006;48: e1-148. erratum in J Am Coll Cardiol.2007;49:1014.

2. Brown JM, O'Brien SM, Wu Ch, Sikora JA, Griffith BP, Gammie JS. Isolated aortic valve replacement in North America comprising 108687 patients in 10 years: changes in risks, valve types, and outcomes in the Society of Thoracic Surgeons National Database. J Thorac Cardiovasc Surg. 2009;137:82-90.

3. McClure RS, Narayanasamy N, Wiegerinck E, Lipsitz S, Maloney A, Byrne JG, et al. Late outcomes for aortic valve replacement with the Carpentier-Edwards pericardial bioprosthesis: up to 17-year follow-up in 1000 patients. Ann Thorac Surg. 2010;89:1410-6.

4. Olsen LK, Engstrom T, Sndergaard L. Transcatheter valve-in-valve implantation due to severe aortic regurgitation in a degenerated aortic homograft. $J$ Invasive Cardiol. 2009;21:E197-200.

5. Ruel M, Chan V, Bedard P, et al. Very long-term survival implications of heart valve replacement with tissue versus mechanical prostheses in adults $<60$ years of age. Circulation. 2007;116:I295-300.

6. Carpentier A. The surprising rise of nonthrombogenic valvular surgery. Nat Med. 2007;13(10):1165-8

7. Seiffert M, Franzen O, Conradi L, et al. Series of transcatheter valve-in-valve implantations in high-risk patients with degenerated bioprostheses in aortic and mitral position. Catheter Cardiovasc Interv. 2010;76:608-15.
8. Bergstralh EJ, Konsanke JL. Computerized matching of cases to controls. Technical Report 56. Department of Health Science Research. Rochester, MN: Mayo Clinic; 1995.

9. Heinze G, Juni P. An overview of the objectives of and the approaches to propensity score analyses. Eur Heart J. 2011;32:1704-8.

10. Rubin DB. The design versus the analysis of observational studies for causal effects: parallels with the design of randomized trials. Stat Med. 2007;26:20-36.

11. Rosenbaum PR, Rubin DB. The central role of the propensity score in observational studies for causal effects. Biometrika. 1983;70:41-55.

12. Akins CW, Miller DC, Turina MI, et al. Guidelines for reporting mortality and morbidity after cardiac valve interventions. J Thorac Cardiovasc Surg. 2008; 135:732-8.

13. Christiansen S, Schmid M, Autschbach R. Perioperative risk of redo aortic valve replacement. Ann Thorac Cardiovasc Surg. 2009;15:105-10.

14. Brown ML, Schaff HV, Lahr BD, Mullany CJ, Sundt TM, Dearani JA, et al. Aortic valve replacement in patients aged 50 to 70 years: improved outcome with mechanical versus biologic prostheses. J Thorac Cardiovasc Surg. 2008;135:878-84.

15. Aymard T, Eckstein F, Englberger L, Stalder M, Kadner A, Carrel T. The Sorin Freedom SOLO stentless aortic valve: technique of implantation and operative results in 109 patients. J Thorac Cardiovasc Surg. 2010;139:775-7.

16. Eggebrecht H, Schäfer U, Treede H, Boekstegers P, Babin-Ebell J, Ferrari M, et al. Valve-in-valve transcatheter aortic valve implantation for degenerated bioprosthetic heart valves. JACC Cardiovasc Interv. 2011;4:1218-27.

17. Hammermeister KE, Sethi GK, Henderson WC, et al. Outcomes 15 years after valve replacement with a mechanical versus bioprosthetic valve: final report of the Veterans Affairs randomized trial. J Am Coll Cardiol. 2000;36:1152-8.

18. Oxenham H, Bloomfield P, Wheatly DJ, et al. Twenty year comparison of a Bjork-Shiley mechanical heart valve with porcine bioprostheses. Heart. 2003;89:715-21.

19. Dunning J, Gao H, Chambers J, Moat N, Murphy G, Pagano D, et al. Aortic valve surgery: marked increases in volume and significant decreases in mechanical valve use-an analysis of 41,227 patients over 5 years from the Society for Cardiothoracic Surgey in Great Britain and Ireland National database. J Thorac Cardiovasc Surg. 2011;142:776-82.e3.

20. Stassano P, Di Tommaso L, Monaco M, et al. Aortic valve replacement: a prospective randomized evaluation of mechanical versus biological valves in patients ages 55 to 70 years. J Am Coll Cardiol Intv. 2009;54(20):1862-8.

21. van Geldorp MWA, Jamieson RE, Kappetein AP, Ye J, Fradet GJ, Eijkemenas MJC, et al. Patient outcome after aortic valve replacement with a mechanical or biological prosthesis: weighing lifetime anticoagulant-related event risk against reoperation risk. J Thorac Cardiovasc Surg. 2009;137:881-6.

22. Ruel M, Kulik A, Lam B, et al. Long-term outcomes of valve replacement with modern prostheses in young adults. Eur J Cardiothorac Surg. 2005;27:425-33.

23. Kahn SS, Trento A, DeRobertis M, et al. Twenty-year comparison of tissue and mechanical valve replacement. J Thorac Cardiovasc Surg. 2001;122:257-69.

24. Chan V, Jamieson WR, Germann E, et al. Performance of bioprostheses and mechanical prostheses assessed by composites of valve-related complications to 15 years after aortic valve replacement. J Thorac Cardiovasc Surg. 2006;131:1267-73.

25. Kulik A, Bedard P, Lam BK, et al. Mechanical versus bioprosthetic valve replacements in middle-aged patients. Eur J Cardiothorac Surg. 2006;30:485-91.

26. Prasongsukarn K, Jamieson WR, Lichtenstein SV. Performance of bioprostheses and mechanical prostheses in age group 61-70 years. J Heart Valve Dis. 2005;14. 501-501.

27. Rahimtoola AH. Choice of prosthetic heart valve in adults: an update. J Am Coll Cardiol. 2010;55(22):2413-26.

28. Marquez S, Hon RT, Yoganathan AP, et al. Comparative hydrodynamic evaluation of bioprosthetic heart valves. J Heart Valv Dis. 2001;10:802-11.

29. Bottio T, Caprilio L, Casarotto D, et al. Small aortic annulus: the hemodynamic performances of 5 commercially available bileaflet valves. J Thorac Cardiovasc Surg. 2004;128:457-62.

30. Kuehnel R-U, Puchner R, Pohl A, et al. Characteristics resistance curves of aortic valve substitutes facilitate individualized decision for a particular patient. Eur J Cardiothorac Surg. 2005;27:450-5.

31. Rahimtoola SH. The year in valvular heart disease. J Am Coll Cardiol. 2006;47: 427-39.

32. Zoghbi WA, Chambers JB, Dumesnil JG, et al. Recommendations for evaluation of prosthetic valves with echocardiography and Doppler ultrasound. J Am Soc Endocardiogr. 2009;22:975-1014.

33. Cohen G, Christakis GT, Joyner CD, et al. Are stentless valves hemodynamically superior to stented valves? A prospective randomized trial. Ann Thorac Surg. 2002;73:767-78. 
34. Chambers JB, Rimington HM, Hodson F, et al. The subcoronary Toronto stentless versus supra-annular Perimount stented replacement aortic valves: early clinical and hemodynamic results of a randomized comparison in 160 patients. J Thorac Cardiovasc Surg. 2006;131:878-82.

35. Biglioli P, Spampinato N, Cannata A, et al. Long-term outcomes of the Carpentier-Edwards pericardial valve prosthesis in the aortic position: effect of patient age. J Heart Valve Dis. 2004;13(Suppl):49-51.

36. Banbury MK, Cosgrove DM, White JA, Blackstone EH, Frater RWM, Okies JE. Age and valve size effect on the long-term durability of the Carpentier-Edwards aortic pericardial bioprosthesis. Ann Thorac Surg. 2001;72:753-7.

37. Benjamin EJ, Wolf PA, D'Agostino RB, Silbershatz H, Kannel WB, Levy D. Impact of atrial fibrillation on the risk of death: the Framingham heart study. Circulation. 1998;98:946-52.

38. Colli A, Verhoye JP, Leguerrier A, Gherli T. Anticoagulation or antiplatelet therapy of bioprosthetic heart valves recipients: an unresolved issue. Eur J Cardiothorac Surg. 2007;31:573-7.
39. ElBardissi AW, DiBardino DJ, Chen FY, Yamashita MH, Cohn LH. Is early antithrombotic therapy necessary in patients with bioprosthetic aortic valves in normal sinus rhythm? J Thorac Cardiovasc Surg. 2010;139:1137-45.

40. Aramendi JI, Mestres CA. Antithrombotic therapy after bioprosthetic aortic valve replacement. Eur J Cardiothorac Surg. 2008;33:529-30.

41. Aupart MR, Mirza A, Meurisse YA, et al. Perimount pericardial bioprosthesis for aortic calcified stenosis: 18-year experience with 1133 patients. J Heart Valve Dis. 2006;15:768-76

42. Mohty D, Dumesnil JG, Echahidi N, et al. Impact of prosthesis patient mismatch on long-term survival after aortic valve replacement: influence of age, obesity and left ventricular dysfunction. J Am Coll Cardiol. 2009;53:39-47.

43. Rahimtoola SH. The year in valvular heart disease. J Am Coll Cardiol. 2010; 55(16):1749-52.

44. Wyss TR, Bigler M, Stalder M, et al. Absence of prosthesis-patient mismatch with the new generation of Edwards stented aortic bioprosthesis. Interact Cardiovasc Thorac Surg. 2010;10:884-7. 